\title{
Learning Community-based Model in the Context of Teacher-parent Partnerships: A Novel Model for Preparing Post-disaster Recovery and Resilience for Students in Risk Disaster Areas in Indonesia
}

\author{
Abdurrahman ${ }^{1 *}$, Budi Kadaryanto ${ }^{2}$, Diah Utaminingsih ${ }^{3}$ and Wini Tarmini ${ }^{4}$ \\ 'Department of Math and Science Education, University of Lampung, Indonesia; \\ abdurrahman.1968@fkip.unila.ac.id \\ 2Department of Language and Art Education, University of Lampung, Indonesia; \\ budi.kadaryanto@fkip.unila.ac.id \\ ${ }^{3}$ Department of Educational Sciences, University of Lampung, Indonesia; \\ diah.utaminingsih@fkip.unila.ac.id \\ ${ }^{4}$ Muhammadiyah University of Prof. Dr. HAMKA, Jakarta, Indonesia; \\ wtarmini@yahoo.com
}

\begin{abstract}
Objectives: Current research is intended to propose a new model for preparedness post-disaster awareness based on learning community approach, namely "Learning Community Cycle Model for Disaster Awareness (LC2MDA)". Methods/ Statistical Analysis: This learning community model was developed by using the research and development method in Lampung province, Indonesia, specifically in the Lampung Barat and the Pesisir Barat districts. The subjects of the research were the students, parents, and teachers. Students were treated as the object for the LC2MDA model, the teachers had a role in facilitating the students achieving the expected set of competence, while the parents took part in giving inputs and considerations to for the school and teachers in integrating disaster literacy into the local curriculum and played a role as active observers of the teaching learning process. Findings: This paper highlights an adapted learning community model. Based on the result of qualitative investigations, it was found that the learning community approach was potentially effective in facilitating students' disaster literacy, attitudes, and skills for preparing post-disaster recovery and resilience. The role shift needed to embed and to extend the optimalization of teacher-parents involvement in the school programs which was achieved through positive supports and commitment to engage in school development program. Application: LC2MDA can be considered as an effective model to recover the post-disaster psychological condition of the students and form the students' psychological resilience to the possibility of the aftershocks.
\end{abstract}

Keywords: Disaster Education, Learning Community, Recovery, Resilience

\section{Introduction}

Indonesia is a country located along the Indian Ocean where the four tectonic plates-the Australian, Philippine, Eurasia and Pacific plates-meet. Therefore, Indonesia is one of the most vulnerable countries to plate-related earthquakes and its accompanying impact i.e., tsunami ${ }^{1}$. In another words, Indonesia, as one of the world's most highly disaster-prone countries often faces multiple hazards resulting in natural disasters such as earthquakes, tsunamis, volcanic eruptions, floods, landslides, drought, and forest fires. These have brought about an awareness of the importance of public disaster prevention education and have made it a great urgency in Indonesia ${ }^{2-4}$. In the context of human view, Indonesia ranks first in tsunami hazards out of 76 countries, first in landslides among 162

*Author for correspondence 
countries, third rank in earthquakes out of 153 countries, and sixth rank in floods among 162 countries. The development of public disaster education has become a top priority considering the absence of disaster awareness in the past disaster that caused more than 165,708 lives to be lost due to as the result of the 2004 Sumatra-Pacific Ocean tsunami, 1,300 due to the 2005 NIAS Earthquake, 5,778 due to the 2006 Yogyakarta Earthquake, 645 due to the 2006 South Java Tsunami and 1,117 due to the 2010 West Sumatra Earthquake ${ }^{5}$. These have brought about an awareness of the importance of public disaster prevention education and have made it a great urgency in Indonesia, 6 .

Disaster preparedness issues have become a concern of many scholars as a consequence of the increase in unpredictable natural disaster for the last decade $e^{3,7}$. A number of recent studies have explored the influence of students' disaster knowledge, attitude, and skills on disaster preparedness $s^{3,8-10}$. It is acknowledged that advanced preparations for disaster awareness in schools can save lives, reduce injuries, prevent damage to property and critical infrastructure, and recover students' psychological aspect early ${ }^{3,7,11}$. Therefore, disaster education, which includes education on disaster risks, disaster awareness, mitigation and preparedness strategies, is one effort to reducing the destructive impact of disasters early $\underline{12,13}^{13}$.

In the post-disaster recovery, rehabilitation and reconstruction phase, it is critical to prevent the creation of and to reduce disaster risk by "Building Back Better" and increasing public education and awareness of disaster risk in common; disaster reduction education particularly stresses pre-disaster preparedness and emergency response during disasters. Little is mentioned about post-disaster activities or programs, including recovery and resilience as a 'soft solution' for Disaster Risk Reduction (DRR) programs $\frac{13,14}{3}$. In the meantime, although the Indonesian government has some educational resources, they are independent, and there is little collaboration with schools and communities, especially in integrating disaster literacy in to school curriculum 3 . Despite these longstanding education efforts, household preparedness levels as the second alternative for developing children's disaster awareness has remained low and generally unchanged, even while the costs and dangers of catastrophic disasters have increased 15 .

Community-based approaches to disasters are becoming more common place as the development community come to realise the benefits of this approach ${ }^{16}$, which recognizes and values local culture, conditions and development issues ${ }^{17}$. The huge destructive Pacific Ocean tsunami in December 26, 2004, have caused disaster management systems, including community involvement established and led to studies focusing on the influence of school disaster programs in contextual and actual preparedness. However, such studies have remained limited in developing countries including in Indonesia ${ }^{7}$. Therefore, school and community in Indonesia have to collaborate in enhancing the awareness on the importance of the knowledge, attitude, and skills related to community recovery and resilience after disasters. Such collaboration has to be put into action by giving community education both in schools and the community they need to be prepared for encountering any disasters ${ }^{18}$. Several studies have been developed for involving a community in the context of community-based disaster management model for any situations $s^{10,19,20}$. As the characteristics of disasters, cultural, and education systems in Indonesia are different from others, current study will be valuable for enriching different perspectives of learning community model for disaster risk areas in terms of preparedness, recovery, and resilience through intensive collaboration between teachers and parents.

Schools in Indonesia have to collaborate with the community to contribute to the process of translating knowledge attitude and skills for the better preparedness of the community living in the disaster area. Several studies have been developed for involving a community in the context of community-based disaster management model for any situations $s^{10,19,20}$. Because the characteristics of disasters, cultural and education systems in Indonesia are different from other countries with risk disaster areas, this study will be valuable in enriching the different perspectives of learning community model for DRR concerning in preparedness recovery and resilience through collaboration teacher-parents partnership intensively.

\section{The Existing Disaster Resilience of Learning Community Model}

Several studies have been conducted in relation to disaster resilience issues involving learning community. One of them was carried out in $\underline{21}$ who conducted research involving children with their ECE (early childhood education) model for disaster preparedness. However, such research 
did not really involve parents of whom their children have grown and developed in their primary environment, yet rather emphasizing only on teachers. Another learning community model was developed by Cutter in the framework of DROP (Disaster Resilience of Place) which focused on community involvement rather than on individual development ${ }^{19}$. For example, how children can deal with the effect of disasters so they can grow up as adult optimally for long-term period. This research focus on an extensive social system, Ecosystem, and Macro system level, rather than on psychological effect, which is still stuck on children's mind after a disaster occurs. We can see that the advantage of this research is how it developed coping response for every indicator, such as ecology, social, economy, institution, and infrastructure as well as competence community. This concept is represented as nested triangles illustrating how this inherent process occurs at the local scale, resulting in community-level endogenous factors, as well as at the broader scales (larger triangles) which embody exogenous factors.

Chen has also developed other post-disaster treatment models, namely Integrating Community-Based Disaster Management $(\mathrm{ICBDM})^{10}$. The model that is for disaster management in Taiwan includes several stages, such as initiation, assessment, planning, and practice where for each stage involves the active contribution of community-based disaster management organizations. In this case, every member of the community must know the purpose and disaster mitigation strategy to maximize on every phase in this model. This study has also been not focusing on how children build resilience in their primary environment. In other words, parents have not involved much in scaffolding their children. Scaffolding children as well as teachers could be utilized as an alternative method in enhancing their competence ${ }^{22}$. Such competence is particularly related to disaster literacy. Different from other learning community models for disaster resilience, Learning Community Cycle Model for Disaster Awareness (hereafter LC2MDA) has been developed for schools in risk disaster areas conforming to the Indonesian indigenous cultures.

\section{Research Method}

This learning community model was developed by using the research and development method ${ }^{23}$. The location of the research was conducted in Lampung province, Indonesia, specifically in the Lampung Barat and the
Pesisir Barat districts. The objects of research were the students, parents, and teachers. In current model, students were regarded as the object for the LC2MDA model. The outcome of this model was the enhancement of the student's competence/learning outcome in terms of their awareness and resilience. The teachers had a role in facilitating the students achieving the expected set of competence developed in the model, either inside or outside classrooms. Their parents took part in giving inputs and considerations to for the school and teachers in integrating disaster literacy into the local curriculum and played a role as active observers of the teaching learning process. Subsequently, both teachers and parents did reflective activities after the learning to fix the students' learning activities for the betterment of their learning both at the school and at home.

The LC2MDA was developed by using the framework of in $\frac{24,25}{}$ roommates components and indicators both of them has combined supplementary. The step of developing process could be represented in Figure. Stages of developing model are as follows: (a) Building, at this stage the researchers did the exploring literature and resources, preliminary research, and constructing the framework. This stage was the preliminary study which was conducted by applying a qualitative descriptive approach. (b) Defining, at this stage, it was done by analyzing school context, analyzing modality of learners, analyzing the curriculum, defining aims and goals, determining the standards of community empowerment model of development. (c) Designing, at this stage, it was done by selecting the relevant instructional and empowerment components, constructing pre-community empowerment model/prototype I. The development stage of designing the model was by applying the descriptive approach, followed by the application of a limited trial design models with experimental method (single one shot case study). When there is an improvement from the limited test, then it was continued by a broader test with the experimental method (one group pretest-posttest). (d) Developing, at this stage, it was done the evaluation of the first prototype based on the theory and the validates, after the first prototype have been evaluated, prototype II and prototype III will be produced. (e) Validating, at this stage, it was done the validation of the second prototype model based on three valuators by using expert validation instrument. Those three valuators are a Professor in Curriculum Design, Associate Professor on Disaster and Environmental Issues, and a Professor in Science 
Education. Once validated, the prototype II was later corrected and revised again to produce the final product models. Validation of models was using quasi experimental method (non-equivalent pretest-posttest control group design) followed by the development of culture/ school culture that is responsive to potential natural disasters. (f) Disseminating, this stage was the stage of application of the model that has been developed. The phase scheme of this study was presented according to the Figure 1.

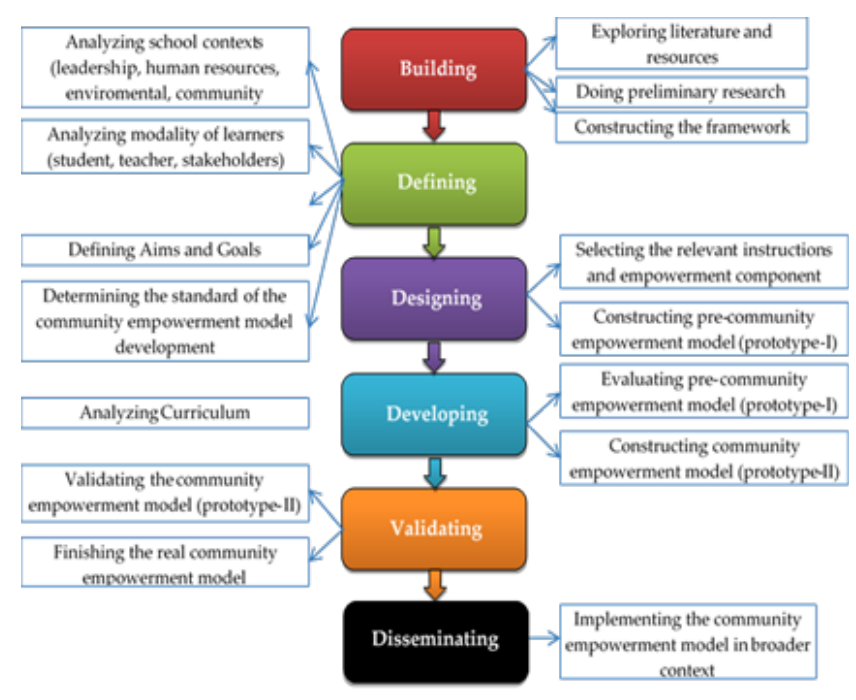

Figure 1. Model development stages ${ }^{25}$.

\section{Result and Discussion}

In this paper we proposed a new model for preparedness post-disaster awareness based on learning community approach, namely "Learning Community Cycle Model for Disaster Awareness (LC2MDA)". The advantage of LC2MDA is student's resilience mapping and supported by community learning. This concept is also in line with some literature, which explains that resilience refers to a social system's ability to give responses and to recover the conditions after a disaster. It focuses on situation after disaster and how to give better responses to threats. Although there are many definitions of resilience, Clinton strongly explained that resilience is the ability to adapt positively to disaster and unexpected specific events, where surrounding social systems have main role $\frac{26}{}$.

Furthermore, compared with other disaster models, LC2MDA has some advantages, those are: (1) focus on specific psychological condition of children; (2) have process to increase resilience after disaster through EXCLUSIVE (Exploring, Clustering, Simulating, Valuing, and Evaluating) syntax learning model that integrated in the model $\frac{27}{}$; (3) involve the nearest social system for the students, parents and teachers; (4) observe supporting and risk factors that make the role of social system can be increased to promote resilience. LC2DMA also mapped how communication pattern between parents and teachers to develop student' recovery and resilience.

The study begins with an introduction that is done through the FGD (Focus Group Discussion) to the students, parents, and teachers at two state elementary schools (SekolahDasarNegeri) in LIWA Lampung Barat. In FGD, students were asked to fill out a few items of questions related to the identification of student's psychological condition post-disaster. One of the question items and students' answer were as follows: "What have made you feel anxious recently?" The answer given was "When listening to the loud sound of a car, seeing the heavy rain, hearing the thunder, seeing the strong winds. All the answers given were related to a natural disaster, they did not have any relations to friendship or academic fields. Their answers were also in line with the result of a depth interview conducted towards 23 parents in West Coast Lampung (Pesisir Barat). Eighteen parents stated that their children were not ready in facing a natural disaster and the rest felt that they were ready to face a natural disaster.

From the analysis of some questions, it can be concluded that (1) students in elementary school have high level of stressors and low attitude of resilience against the natural disaster, (2) there is no communication between parents and teachers (learning community has not been form), (3) parents are not really aware of how to deal with the children experiencing some stress about disasters, and (4) teachers and schools do not have programs for increasing their students' resilience against the natural disaster and (5) disaster curriculum has not been integrated into the teaching learning process in classrooms. The results are then used as the basis to build a framework of LC2MDA development.

Based on the literature studies and reinforcement by the results of the preliminary study, the researchers set out some basic assumptions in the development of LC2MDA model, such as: (1) the LC2MDA developed is merely associated to the process of recovery after natural disasters, and not in the context of disasters caused 
by technological disasters or terrorist acts; (2) LC2MDA focuses on developing students disaster awareness and increasing their resilience in facing natural disasters around through a learning community approach among the students, parents, teachers, and schools; (3) LC2MDA focuses on improving disaster literacy and its impact on the soft skills ability in the context of students psychosocial; and (4) the development of LC2MDA is implemented in the classroom learning process by using integrated thematic learning concept with EXCLUSIVE learning models in order to improve students' disaster literacy ${ }^{27}$. After going through a series of research and development stages, the LC2MDA model is presented in Figure 2.

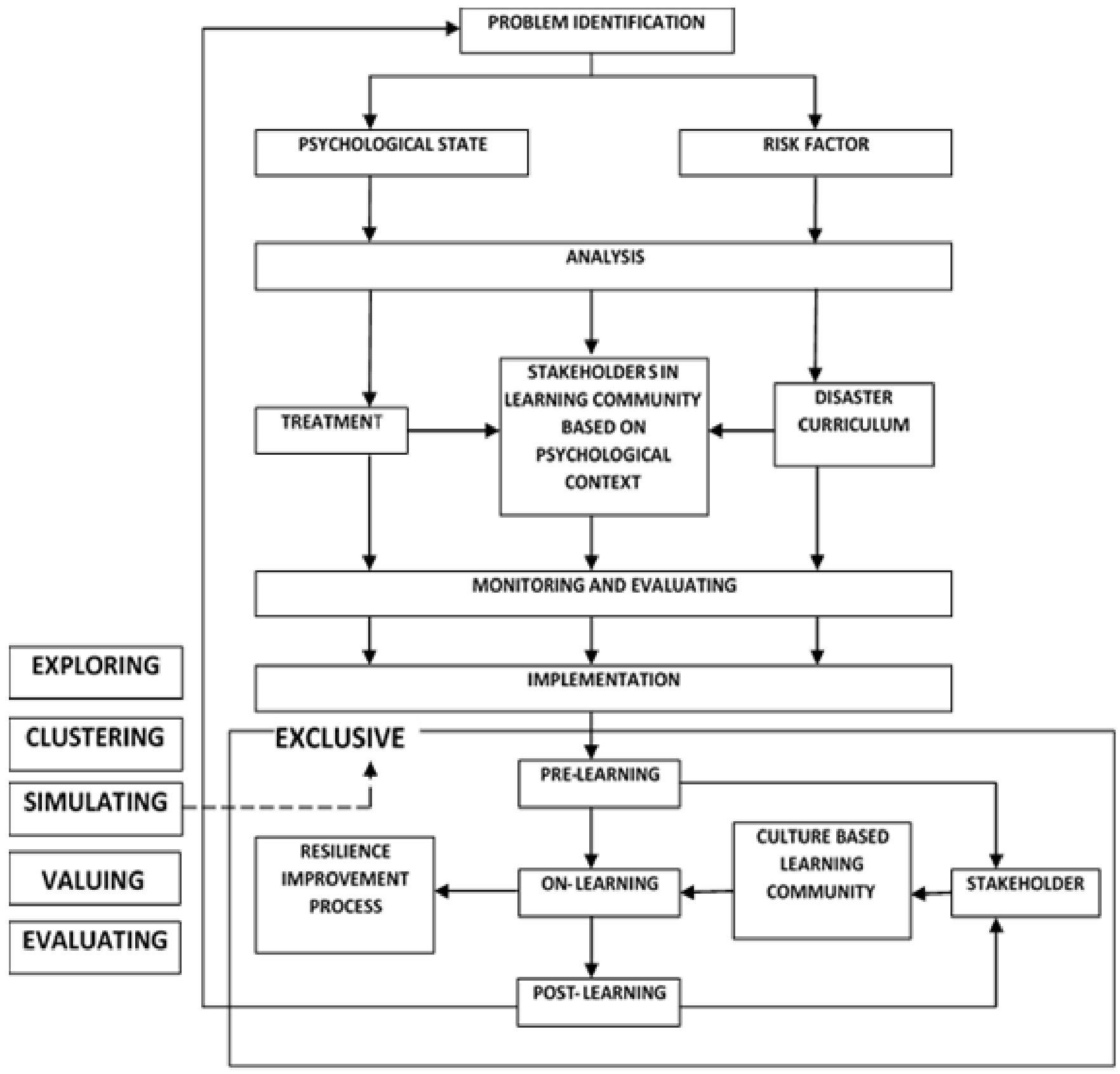

Figure 2. Learning Community Cycle Model for Disaster Awareness (LC2MDA) model.. 


\section{Explanation of the Model}

The early process of LC2MDA is the identification of prior resilience level for the students. In this process, there are few things to be done, such as: identification of the problem, literature study, understanding the local culture and the role of stakeholders, understanding the geological factors, identification of existing knowledge of resilience, identification of students' character which must be constructed.

Once the problem is identified and the psychological condition of the students is mapped, then it is carried out the identification of risk factor. At this stage, things to be done are: to establish the disaster risk context (Psychosocial), identify the worst thing that can happen after the disaster, the risk analysis of post-disaster and ways to enhance their resilience, i.e. the treatment which will be given to students in improving the resilience to postdisaster recovery process.

On the next phase, it is done the identification and analysis of materials covered that include analysis of the Standard Competence (KI) and Basic Competence (KD), identify the types of material or themes of the subjects, select the type of material or theme which is suitable with the standard competence and basic competence, identification and approaches analysis, models, methods, and learning instrument, and preparation for field implementation. At this stage, the learning model used is the EXCLUSIVE model (Exploring, Clustering, Simulating, valuing, and Evaluating) which is specific for disaster mitigation ${ }^{27}$.

After all the preparations for the study has been completed, then it comes to the field implementation phase. It consists of three phases: pre-learning, on-learning and post-learning. In the pre-learning phase, orientation process is done by all stakeholders to engage in recovery activities and establishing the resilience of the students, identification of disaster experience, and motivation. In the on-learning phase, the EXCLUSIVE model begins to be applied which is covered with the learning process to increase disaster literacy and resilience attitude of the students. In the post-learning phase, it is done by conducting an assessment of disaster identification ability, evaluation of the problems and development of disaster solution, forming a community-based disaster management organization. The last step done by all stakeholders (teachers, parents, local government staffs) on this LC2MDA models is evaluating the results of the implementation of the model comprehensively which has been acquired and supervise the follow-up process from the implementation that has been done.

\section{Result from Validators}

\subsection{Eligibility of LC2MDA from the Aspects of Suitability}

The average total score of all three validators regarding the fulfillment of the aspects of the model suitability that has been developed is 3.3 or $81 \%$, which means very high. That means LC2MDA is applicable. It is based on the reason that LC2MDA has already fulfilled the feasible aspects of suitability as follows: (a) LC2MDA which is successfully developed has already included in good criteria related to the main objective in developing a model of community empowerment in disaster-prone areas, (b) LC2MDA is very feasible if it is implemented as a model for community empowerment in disasterprone areas, (c) The concept of LC2MDA is in line with the concept of community empowerment programs in disaster-prone areas, (d) The integration between the whole process of LC2MDA has been accepted as one of a community empowerment programs in disaster-prone, ( e) LC2MDA has already been systematic in order to increase the community participation in learning communities, (f) The workflow or process described in LC2MDA is implementable, ( $\mathrm{g}$ ) the theory and list of references used in the development of LC2MDA has been very relevant, and (h) the language used in LC2MDA to make stakeholders understand has been appropriate. It is in line with Beecham, who stated that suitability is one of the factors that determine the feasibility of a model developed 25 .

\subsection{Feasibility of LC2MDA from the Aspects of Scope}

The average total score of the validates regarding the fulfillment of the scope aspect from the model that has been developed is 3.4 or $85 \%$, which means very high. It means that LC2MDA in terms of scope are feasible to be applied. It is based on the reason that LC2MDA meets the criteria of the scope aspects as follows: (a) LC2MDA as a model that focuses on disaster mitigation, communitybased learning community has been satisfied, (b) the level of LC2MDA phase detail related to the purpose of 
development and implementation, especially in the neighborhood school with the vulnerability level of disaster has been specific, (c) the phase of LC2MDA which is successfully developed to involve stakeholders in the whole process that is both theorists and technical based on the development goals has been already in a good criteria, (d) the phase of LC2MDA whichare able to represent all the main processes of the model of community empowerment in vulnerable disaster areas has been very good, and (e) LC2MDA is very possible to be applied directly to the community with a heterogeneous background. It is in line with Beecham who stated that the scope is one of the factors that determine the feasibility of a model developed.

\subsection{Feasibility of LC2MDA from the Aspect of Consistency}

The average total score of the valuators regarding the fulfillment of the consistency aspect of the model that has been developed is 4 or $100 \%$, which means very high. That means LC2MDA in terms of consistency are feasible to apply. It is based on the reason that LC2MDA meets the criteria of consistency with the following aspects: (a) the use of terms in LC2MDA has been very consistent, (b) the use of language in LC2MDA has been very consistent, (c) the structure of LC2MDA which is presented has been very consistent.

\subsection{Feasibility of LC2MDA from the Aspect of Clarity}

The average total score of validate regarding the fulfillment of clarity aspect of the model that has been developed is 3.6 or $96 \%$, which means very high. It means that LC2MDA in terms of clarity are feasible to be applied. It is based on the reason that LC2MDA meets the criteria of the aspects of clarity as follows: (a) the terms used in LC2MDA is very clear, (b) the language used in LC2MDA has been very clear, (c) easy to understand the operational phase of LC2MDA, (d) the presentation of LC2MDA (chart/schematic plot and descriptive) is obvious, and (e) the relationship of the chart/plot scheme with a descriptive explanation of LC2MDA is clear.

\subsection{Feasibility of LC2MDA from the Aspects of Ease of Use}

The average total score of the validate regarding the fulfillment of ease of use aspect from the model that has been developed is 3 or $75 \%$, which means high. It means that
LC2MDA in terms of ease of use are feasible to be applied. It is based on the reason that LC2MDA meets the criteria of the ease of use aspects as follows: (a) prior knowledge required by the user to interpret the operational framework of LC2MDA is only slightly, (b) based on the phase of operations that have been described in LC2MDA, the steps are easy to understand, (c) based on the phase of operations that have been described in LC2MDA, the steps are easy to apply, (d) the description of the phase of operations in LC2MDA can be easier for users to apply the LC2MDA, (e) LC2MDA is easily adapted to different situations in the context of mitigation for disaster in general.

\subsection{Feasibility of LC2MDA from the Aspects of Depth}

The average total score of the validate regarding the fulfillment of the depth aspect of the model that has been developed is 3.7 or $92 \%$, which means very high. It means that LC2MDA in terms of depth usage are feasible to be applied. It is based on the reason that LC2MDA meets the criteria of the depth aspects as follows: (a) LC2MDAhas already been characteristic related to the development objectives and the context of the problems encountered, (b) the specificity ofLC2MDAwith the context of the situation which is encountered has been specific, and (c) LC2MDA operational phase related to the development objectives and the context of the situation encountered has been detailed.

\subsection{Feasibility LC2MDA of Aspects Operational}

The average total score of the validate regarding the fulfillment of operational aspects of the model that has been developed is 3.5 or $88 \%$, which means very high. It means that LC2MDA in terms of operational are feasible to be applied. It is based on the reason that LC2MDA meets the criteria of operational aspects as follows: (a) LC2MDA is possibly implemented in an organized and structured way by involving all stakeholders and (b) LC2MDA has already been operational to improve the disaster awareness and resilience against the disaster risk.

\section{Conclusion}

Based on the research, it showed that LC2MDA can be considered as an effective model to recover the postdisaster psychological condition of the students and form 
the students' psychological resilience to the possibility of the aftershocks. After model has been successfully developed, the next step is to expand the implementation of the LC2MDA model in more schools or communities, develop a set of common learning and empowerment indicators embed in model, and then set up the disaster community. LC2MDA should facilitate the guideline in local communities' participation in building community resilience and can be applied more sustainable practices. Further impact, application of the model can contribute on the government policy changes in managing economic, social, and environmental needed to enhance student resilience.

\section{Acknowledgement}

Grateful to all of the Science Education for Disaster Technology PER group, especially M. Sarkowi, who provided advices for developing model, and Prof. Bujang Rahman, who mentored us through this project. Funding for this project was provided by the Ministry of Research, Technology, and higher Education with Grant No. 161/ UN26/8/LPPM/2016.

\section{References}

1. Global assessment report on disaster risk reduction (GAR) Indonesia-risk profile. United Nations Office for Disaster Risk Reduction (UNISDR); 2009. p. 1-207.

2. Hayashi T. Disaster prevention education in Merapi Volcano Area Primary Schools: Focusing on student's perception and teacher's performance. Procedia Environmental Sciences. 2014; 20:668-77. https://doi.org/10.1016/j.proenv.2014.03.080.

3. Hayashi T. Educational merits of lecturing and discussion methodsin teaching disaster prevention: Toward improvement of student's knowledge, attitude, and behavior in Merapi Volcano area primary schools. Journal of Disaster Research. 2014; 9(5):870-8. https://doi.org/10.20965/jdr.2014.p0870.

4. Sugimoto M, Iemura $H$, Shaw R. Tsunami height poles and disaster awareness: Memory, education and awareness of disaster on the reconstruction for resilient city in Banda Aceh, Indonesia. Disaster Prevention and Management: An International Journal. 2010; 19(5):527-40. https://doi.org/10.1108/09653561011091869.

5. UNDP United Nations Development Programmed -Indonesia. [Internet]. [cited 2017 Oct 10]. Available from: http://www.id.undp.org/content/dam/indonesia/docs/ AR2013/AR\%20UNDP\%202012-2013_high-res. pdf?download.

6. Gwee Q, Takeuchi Y, Jet-Chau W, Shaw R. Disaster education system in Yunlin County, Taiwan. Asian Journal of Environment and Disaster Management. 2011; 3(2):189204. https://doi.org/10.3850/S1793924011000745.

7. Kanegae H. Effectiveness of disaster-based school program on students' earthquake-preparedness. Journal of Disaster Research. 2013; 5(8):1009-17.

8. Soffer Y, Goldberg A, Avisar-Shohat G, Cohen R, Bar-Dayan Y. The effect of different educational interventions on schoolchildren's knowledge of earthquake protective behavior in Israel. Disasters. 2010; 34(1):205-13. https://doi.org/10.1111/j.1467-7717.2009.01125.x. PMid:19793325

9. Ronan KR, Crellin K, Johnston DM. Correlates of hazards education for youth: A replication study. Nat Hazards. 2010; 53(3):503-26. https://doi.org/10.1007/s11069-0099444-6.

10. Chen LC, Liu YC, Chan KC. Integrated community-based disaster management program in Taiwan: A case study of Shang-an village. Natural Hazards. 2006; 37(1-2):209-23. https://doi.org/10.1007/s11069-005-4669-5.

11. Smith K. Environmental hazards: Assessing risk and reducing disaster. London: Routledge; 1993. p. 1-306.

12. Mulyasari F, Takeuchi Y, Shaw R. Implementation tools for disaster education. Community Environment and Disaster Risk Management. 2011; 7:137-51. https://doi.org/10.1108/S2040-7262(2011)0000007013.

13. Rafliana I. Disaster education in Indonesia: Learning how it works from six years of experience after Indian Ocean Tsunami in 2004. Journal of Disaster Research. 2004; 7(1):83-91. https://doi.org/10.20965/jdr.2012.p0083.

14. ThiMyThi T, Shaw R. Building disaster resilience from school level: A case study in Thua Thien Hue Province, Central Vietnam. Journal of Disaster Research. 2013; 8(1):206-6.

15. Paton D, Sagala S, Okada N, Jang L, Burgelt PT, Gregg CE. Making sense of natural hazard mitigation: Personal, social and cultural influences. Environmental Hazards. 2010; 9(2):183-96. https://doi.org/10.3763/ehaz.2010.0039.

16. Uitto JI, Shaw R. Adaptation to changing climate: Promoting community-based approaches in the developing countries. SANSAI: An Environmental Journal for the Global Community. 2006; 1:93-107.

17. Ayers JM, Huq S. Supporting adaptation to climate change: What role for official development assistance? Development Policy Review. 2009; 27(6):675-92. https://doi.org/10.1111/j.1467-7679.2009.00465.x. 
18. Murata F, Imamura K, Katoh Y, Kawata S, Takayama T. Tsunami: To survive from tsunami. Singapore: World Scientific; 2010.

19. Cutter SL, Barnes L, Berry M, Burton C, Evans E, Tate E, Webb J. A place-based model for understanding community resilience to natural disasters. Global Environmental Change. 2008; 18(4):598-606. https://doi.org/10.1016/j.gloenvcha.2008.07.013.

20. Sweetland SR, Hoy WK. School characteristics and educational outcomes: Toward an organizational model of student achievement in middle schools. Educational Administration Quarterly. 2006; 36(5):703-29. https://doi.org/10.1177/00131610021969173.

21. Fikriani D, Bone J. Children's participation in disaster risk reduction as curriculum. New Zealand Research in Early Childhood Education. 2014; 17:35-50.

22. Rahman B, Abdurrahman A, Kadaryanto B, Rusminto NE. Teacher-based scaffolding as a teacher professional development program in Indonesia. Australian
Journal of Teacher Education. 2015; 40(11):1-13. https://doi.org/10.14221/ajte.2015v40n11.4.

23. Gall MD, Gall JP, Borg WR. Action research. Educational Research: An Introduction. Pearson Education. Inc. Boston; 2003. p. 578-97.

24. Thiagarajan S. Instructional development for training teachers of exceptional children: A sourcebook; 1974.

25. Beecham S, Hall T, Rainer A. Defining a requirements process improvement model. Software Quality Journal. 2005; 13(3):247-79. https://doi.org/10.1007/s11219-005-1752-9.

26. Clinton J. Resilience and recovery. International Journal of Children's Spirituality. 2008; 13(3):213-22. https://doi. org/10.1080/13644360802236474.

27. Abdurrahman, Tarmini W, Kadaryanto B, Development of meta cognitive skills-oriented learning model to enhance literate and awareness character for elementary student at risk area. Proceeding of National Seminar of Science Education; 2012. 